\title{
Chapter 12 \\ Implications of the Developed Scenarios for Climate Change
}

\author{
Malte Meinshausen
}

\begin{abstract}
This section provides a summary of the implications of the developed $2.0{ }^{\circ} \mathrm{C}$ and $1.5^{\circ} \mathrm{C}$ scenarios for global mean climate change. Specifically, we consider atmospheric $\mathrm{CO}_{2}$ concentrations, radiative forcing, global-mean surface air temperatures and sea level rise.
\end{abstract}

The question addressed in this section is what the implications are for future climate change if the world were to follow the energy-related $\mathrm{CO}_{2}$ emissions developed here, complemented by land-use $\mathrm{CO}_{2}$ emissions and those of other greenhouses gases (GHGs). According to the high-emission scenario with unabated fossil fuel use, the world could experience 1400 ppm $\mathrm{CO}_{2}$ concentrations by the end of 2100 , which is five times higher than the pre-industrial background concentration of $278 \mathrm{ppm}$. Our ice-core records have shown that over the last 850,000 years, the $\mathrm{CO}_{2}$ concentrations have only oscillated between approximately $180 \mathrm{ppm}$ and $280 \mathrm{ppm}$. In fact, for the last 10 million years on this planet, the $\mathrm{CO}_{2}$ concentrations have probably not exceeded the $\mathrm{CO}_{2}$ concentrations that our thirst for fossil fuels would propel the world into in just two centuries.

That is a dramatic change to the thin layer of atmosphere that wraps our planet. Even if any climate change consequences that follow from this dramatic change in $\mathrm{CO}_{2}$ concentrations are disregarded, the consequences will be dramatic. At atmospheric $\mathrm{CO}_{2}$ concentrations above 900 ppm, the acidity level in the oceans will drop below the so-called 'aragonite saturation level', which is the level required for coral reefs and other organisms with calciferous shells to sustain their structures (Ricke et al. 2013). Therefore, without even considering ocean warming and the associated bleaching, this would mean the end of much marine life as we know it.

M. Meinshausen $(\bowtie)$

Australian-German Climate and Energy College, University of Melbourne, Parkville,

Victoria, Australia

e-mail: malte.meinshausen@unimelb.edu.au 


\subsection{Background on the Investigated Scenarios}

The international community uses various scenarios to explore these future changes to $\mathrm{CO}_{2}$, involving other GHGs and ultimately, temperature, precipitation changes, and changes involving extreme events. Here, we compare the scenarios developed in this study with the standard scenarios developed for the forthcoming Intergovernmental Panel on Climate Change (IPCC) Sixth Assessment Report. The scenarios used in the forthcoming IPCC Sixth Assessment Report are the so-called 'SSP scenarios'. The full range of those nine SSP scenarios spans cases of unabated fossil fuel use at the higher-emissions end to two scenarios at the lower-emission end that are considered to be consistent with a $2{ }^{\circ} \mathrm{C}$ and $1.5{ }^{\circ} \mathrm{C}$ warming target. These two scenarios are called 'SSP1_26' and 'SSP1_19', respectively.

Both of those lower-emissions scenarios imply a substantial amount of biomass use for energy, combined with CCS, to draw down atmospheric $\mathrm{CO}_{2}$ levels. This is the key difference from the scenarios developed in the present study. Whereas we use a substantial amount of negative $\mathrm{CO}_{2}$ emissions in the reforestation and forest restoration options, our analysis does not depend on the assumption that biomass, combined with CCS, must be used on large scale to achieve either the $2{ }^{\circ} \mathrm{C}$ or $1.5^{\circ} \mathrm{C}$ target.

If we do not rely on some negative $\mathrm{CO}_{2}$ emission options, in particular biomass and CCS, the questions are: (1) to what extent are those negative emissions created by other means (e.g., reforestation); or (2) whether $\mathrm{CO}_{2}$ emissions can be reduced in the first place so that we do not need to rely on negative emissions options; or (3) whether other non- $\mathrm{CO}_{2}$ gases can be reduced even further to make negative $\mathrm{CO}_{2}$ emissions unnecessary. The scenarios developed in this study use all three options, as outlined in the previous chapters. Not only will energy-related $\mathrm{CO}_{2}$ emissions be radically reduced, $\mathrm{CO}_{2}$ uptake via reforestation and forest restoration will also play an important role. This study takes a more conservative approach to non- $\mathrm{CO}_{2}$ gases by being consistent with other stringent mitigation scenarios. Thereby, we ensure that the feasibility constraints implicitly or explicitly set by other modelling frameworks are not violated.

\subsection{Comparison of Atmospheric $\mathrm{CO}_{2}$ Concentrations and Radiative Forcing}

As mentioned above, unabated fossil fuel use over the last century and the twentyfirst century will dramatically change the oceans, simply by creating an atmospheric $\mathrm{CO}_{2}$ concentration beyond that present on the Earth for the last 10 million years. Currently, we just exceeded the historical maximum level of $400 \mathrm{ppm}$ atmospheric $\mathrm{CO}_{2}$ and are continuing to add 2-3 ppm a year. If we consider the most stringent mitigation scenario used in the preparation of the forthcoming IPCC Sixth Assessment Report, SSP1_19, then we will reach 400 ppm concentrations again in the latter half of the century. Staying below $400 \mathrm{ppm}$ is a prerequisite in the long term for remaining below $2{ }^{\circ} \mathrm{C}$ or reaching $1.5^{\circ} \mathrm{C}$ warming. 
Figure 12.1 shows the global $\mathrm{CO}_{2}, \mathrm{CH}_{4}$, and $\mathrm{N}_{2} \mathrm{O}$ concentrations under the key $\mathrm{RCP}$ and SSP scenarios and the three scenarios developed as part of this study. Our $1.5{ }^{\circ} \mathrm{C}$ scenario is clearly lower in terms of its $\mathrm{CO}_{2}$ concentrations than the lowest SSP scenario, SSP1_19, for practically the entire twenty-first century (upper panel). Only towards the end of the twenty-first century do the strongly negative $\mathrm{CO}_{2}$ emissions in the SSP1_19 scenario bring the $\mathrm{CO}_{2}$ concentration closer towards our $1.5^{\circ} \mathrm{C}$ scenario.

Aggregating all the greenhouse gas and aerosol emissions by their radiative forcing, and expressing the resulting radiative forcing again as if it were only caused by $\mathrm{CO}_{2}$ yields the so-called ' $\mathrm{CO}_{2}$ equivalence concentrations'. In Fig. 12.2, the $\mathrm{CO}_{2}$ equivalence concentrations for the four RCP scenarios, the nine SSP scenarios, and three scenarios developed in this study are shown. The reference scenario in this study is quite similar to both the RCP6.0 and SSP4_60 scenarios, providing a medium-high reference case. The radiative forcing and $\mathrm{CO}_{2}$ equivalence concentration of the $2{ }^{\circ} \mathrm{C}$ scenario of this study is actually quite closely aligned with the lower SSP1_19 scenario, at least initially until the middle of the second half of this century. Thereafter, the net negative $\mathrm{CO}_{2}$ emissions implied by the SSP1_19 scenario lead to stronger reductions in radiative forcing than the $2.0^{\circ} \mathrm{C}$ scenario of our study. However, our lower $1.5^{\circ} \mathrm{C}$ scenario first undercuts the radiative forcing trajectory of the SSP1_19 scenario, but then ends up at a similar radiative forcing level by 2100 .

Figure 12.2 shows $\mathrm{CO}_{2}$ equivalence concentrations (upper panel) and radiative forcing (lower panel) of the main scenarios used in IPCC Assessment Reports and this study's scenarios. The RCP scenarios (shown in thin dotted lines) underlie the IPCC Fifth Assessment Report and the so-called 'SSP scenarios' provide the main basis for the scenarios considered in the IPCC Sixth Assessment Report. The three scenarios developed in this study are shown in thick blue lines.

\subsection{Comparison of Cumulative $\mathrm{CO}_{2}$ Emissions}

Since the IPCC Fifth Assessment Report, cumulative $\mathrm{CO}_{2}$ emissions have been introduced as a key metric into the international climate debate. Every tonne of additional $\mathrm{CO}_{2}$ emitted will add to that cumulative burden and warm the planet for the next hundreds and in fact thousands of years. The only way to halt further global warming is to halt cumulative $\mathrm{CO}_{2}$ emissions, which means bringing the annual $\mathrm{CO}_{2}$ emissions to basically zero levels. Only with net negative emissions can the temperature thermostat of the Earth be dialled back again. Therefore, while achieving such net negative emissions is tremendously challenging, it is the only way to maintain long-term climate change at levels close to those of today or well below $1.5^{\circ} \mathrm{C}$. Few scenarios include very strong near-term reductions and no substantially negative $\mathrm{CO}_{2}$ emissions and can limit the temperature increase to $1.5^{\circ} \mathrm{C}$, with no or only a slight overshoot (IPCC Special Report on $1.5^{\circ} \mathrm{C}$ ). In this study, as well as very strong near-term reductions in energy-related $\mathrm{CO}_{2}$ emissions, we have used a range of land-use-based sequestration options. These are not unambitious, as 

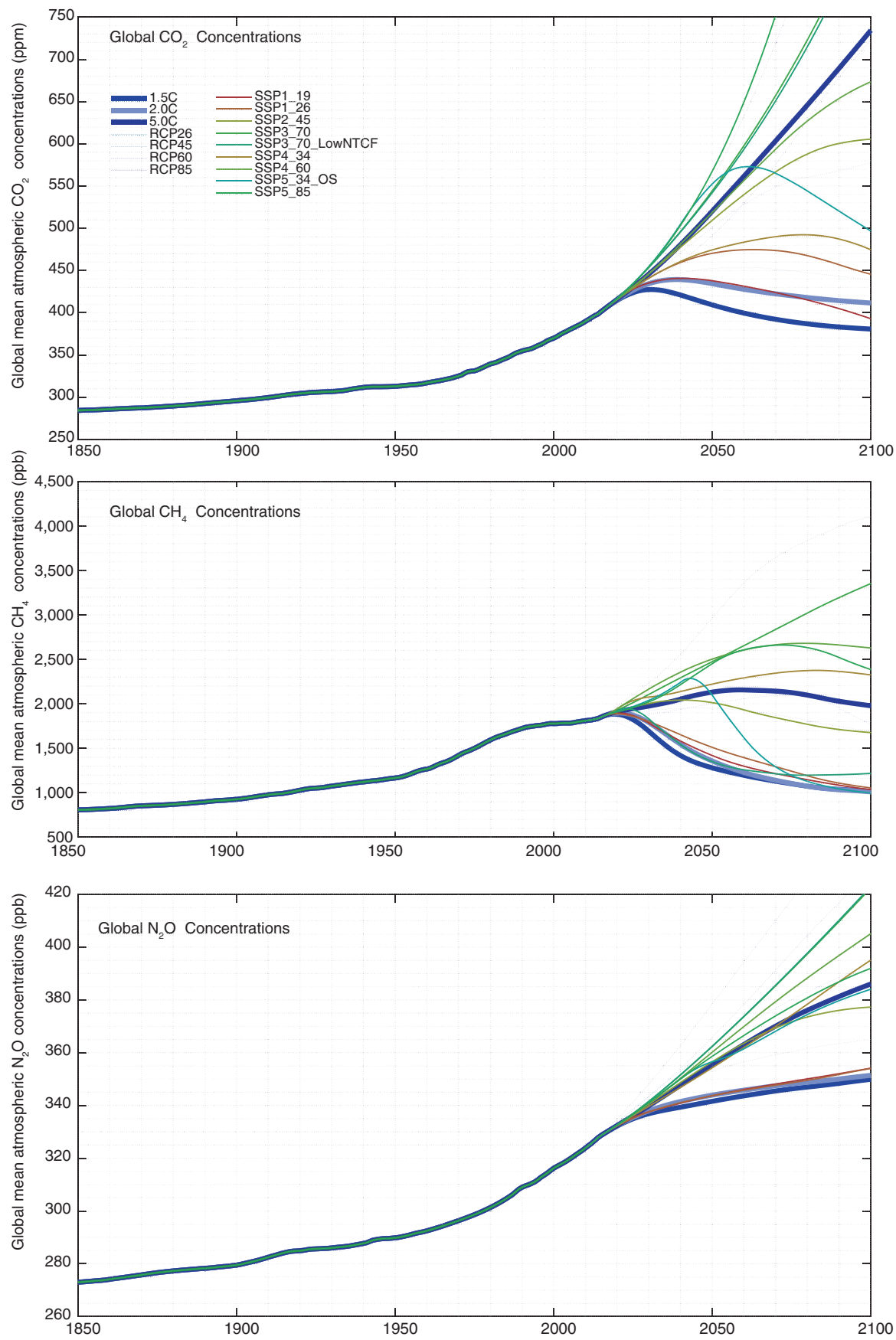

Fig. 12.1 Global $\mathrm{CO}_{2}, \mathrm{CH}_{4}$ and $\mathrm{N}_{2} \mathrm{O}$ concentrations under various scenarios. The so-called SSP scenarios are going to inform the Sixth Assessment Report by the IPCC, the RCP scenarios are the previous generation of scenarios and the LDF scenarios are those developed in this study 

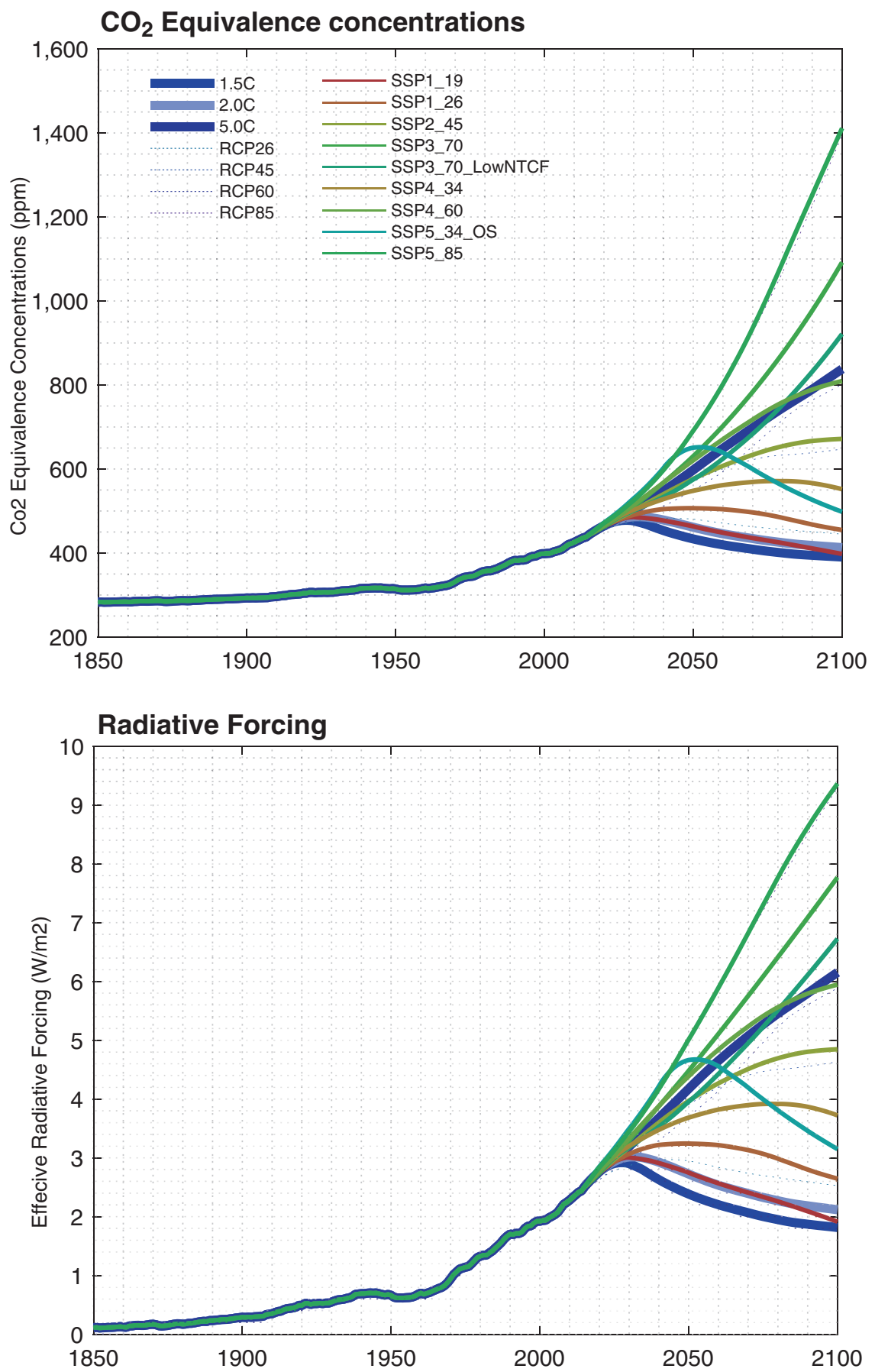

Fig. 12.2 $\mathrm{CO}_{2}$ equivalence concentrations and radiative forcing of main IPCC scenarios for the forthcoming Sixth Assessment (so-called SSP scenarios), the RCP scenarios underlying the Fifth IPCC Assessment Report and the LDF scenarios developed in this study 


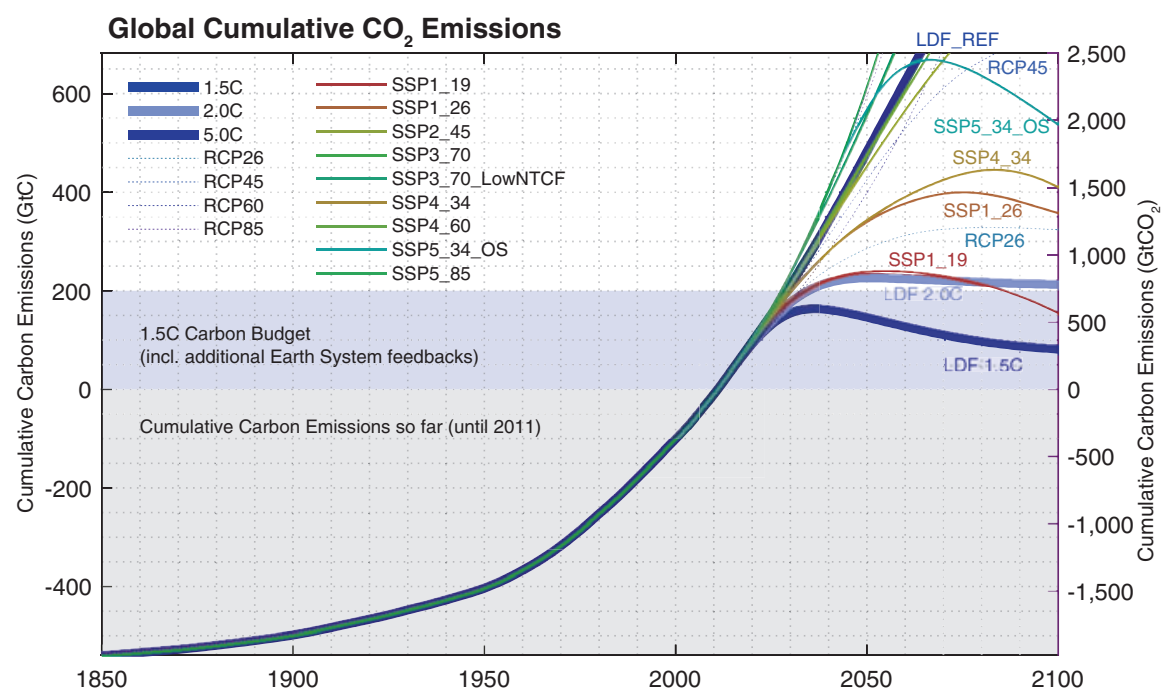

Fig. 12.3 Global cumulative $\mathrm{CO} 2$ emissions $-2.0^{\circ} \mathrm{C}$ and $1.5^{\circ} \mathrm{C}$ scenarios

outlined in previous chapters. In fact, in the case of the $1.5^{\circ} \mathrm{C}$ scenario, they practically require that the Earth's forests be returned to their pre-industrial coverage - a substantial challenge given the widespread deforestation that has occurred over the last 100 years. By the end of the century, the cumulative $\mathrm{CO}_{2}$ emissions beyond levels will constitute around $300 \mathrm{GtCO}_{2}$ (see Fig. 12.3).

Without going into too much detail about why cumulative emission numbers differ between various studies, the key point is that $\mathrm{CO}_{2}$ emissions must be reduced to zero. Otherwise, cumulative emissions and global warming will continue to increase. Therefore, there is no way to avoid emissions-free electricity, transport, and industrial systems, that either learn to completely get rid themselves of fossil fuels or to compensates for any remaining use, either by CCS or land-based sequestration. Because the latter negative emissions option must be used to offset some remaining agricultural emissions, the story becomes simpler. There is no way around the fast and complete cessation of all fossil fuel use. This is the simple and powerful logic of carbon budgets.

Global cumulative $\mathrm{CO}_{2}$ emissions for the scenarios developed in this study (thick blue lines) and other literature-reported scenarios from the RCP and SSP sets. It is clear that this study's $2.0{ }^{\circ} \mathrm{C}$ pathway initially reaches a similar cumulative emissions level as the SSP1_19 scenario, before the cumulative $\mathrm{CO}_{2}$ emissions are reduced again in SSP1_19 with large-scale net negative $\mathrm{CO}_{2}$ emissions via bioenergy with carbon capture and storage. In contrast, the reduction of cumulative $\mathrm{CO}_{2}$ emissions in this study's $1.5^{\circ} \mathrm{C}$ scenarios starts to plateau much earlier (by 2035) and are then reduced by land -based sequestration options, such as reforestation and forest restoration (thick blue line at the lower end). The stated blue $1.5^{\circ} \mathrm{C}$ carbon 
budget range is the effective central value presented in the recent IPCC Special Report on $1.5^{\circ} \mathrm{C}$ warming. ${ }^{1}$

\subsection{Implications for Temperature and Sea-Level Rise}

This section examines the implications of the three scenarios developed in this study for the probabilistic global mean temperature and sea level rise. Based on the latest version 7 of the reduced complexity carbon cycle and climate model MAGICC, we can derive a range of projections for every scenarios that provides a good measure of the projection uncertainties over the twenty-first century. We ran this model 600 times for each scenario, varying wide ranges of feedback and forcing parameters. For the sea-level rise projections, we used the new sea-level rise module of MAGICC7, as described by Nauels et al. (2017) and drove that with our probabilistic temperature projections. We did not include the recent finding that possible Antarctic ice sheet instability could lead to a much greater sea-level rise this century. These extra contributions to sea-level rise are also assumed to affect the higher end of the projections for high-emission scenarios, and do not therefore change the sea-level rise projections of the lower-emissions scenarios.

A key question regarding future temperature projections is whether the scenarios will stay below the envisaged $1.5{ }^{\circ} \mathrm{C}$ and $2.0{ }^{\circ} \mathrm{C}$ warming levels relative to preindustrial levels. When answering this question in terms of the consistency of the $1.5{ }^{\circ} \mathrm{C}$ and $2.0^{\circ} \mathrm{C}$ warming levels, the uncertainty in historical reconstructions of temperatures must play a role. The latest IPCC Special Report on $1.5{ }^{\circ} \mathrm{C}$ warming estimated from an average of four studies that the difference between early-industrial (1850-1900) and recent surface air temperature levels (2006-2015) was $0.97{ }^{\circ} \mathrm{C}$. If we accept here the slightly oversimplified assumption that the 1850-1900 temperature levels can be equated with pre-industrial temperatures, we can evaluate the difference towards a $1.5^{\circ} \mathrm{C}$ warming level, namely $0.53{ }^{\circ} \mathrm{C}$. Note that this distance could be shorter - a matter of ongoing scientific debate.

Anyway, the median temperatures for the (lowest) $1.5^{\circ} \mathrm{C}$ Scenario in this study do indeed—somewhat by design—reach the $1.5^{\circ} \mathrm{C}$ target level by 2100 . This means that after a slight overshoot, there will be a $50 \%$ chance by 2100 that the global mean temperature is at or below $1.5^{\circ} \mathrm{C}$ warming-and without the widespread deployment of bioenergy with carbon capture and storage (BECCS).

\footnotetext{
${ }^{1}$ The IPCC Special Report estimates for a $0.53{ }^{\circ} \mathrm{C}$ distance of the $1.5{ }^{\circ} \mathrm{C}$ degree target from the 2006-2015 level, a carbon budget of $560 \mathrm{GtCO}_{2}$ from 1 January 2018 onwards. Reduced by 100 $\mathrm{GtCO}_{2}$ for additional Earth System Feedbacks (see Table 2.2 in the IPCC Special Report on $1.5^{\circ} \mathrm{C}$ ) and adding approximately $270 \mathrm{GtCO}_{2}$ emissions for the period from 2011 to 2017 , the central estimate for a $50 \%$ chance of staying below $1.5{ }^{\circ} \mathrm{C}$ warming as stated by IPCC is approximately $730 \mathrm{GtCO}_{2}$ from 2011 onwards. This is for a definition of historical warming that is based on a consistent surface air temperature estimate over the land and oceans. A further reduction of approximately $150 \mathrm{GtCO}_{2}$ would result, if we take into account that the IPCC carbon budget estimate refer to a $1850-1900$ early industrial reference period for the $1.5^{\circ} \mathrm{C}$ warming, rather than a 1750 pre-industrial reference period (which makes approximately a $0.1^{\circ} \mathrm{C}$ difference, with +-0.1 ${ }^{\circ} \mathrm{C}$ uncertainty).
} 
In the case of our $2{ }^{\circ} \mathrm{C}$ Scenario, the centric $66 \%$ range is almost entirely below the $2{ }^{\circ} \mathrm{C}$ warming level, which means that the chance of maintaining temperature change below $2{ }^{\circ} \mathrm{C}$ is $80 \%-85 \%$, in the modelling framework used. This warming level and likelihood fits well with the adapted Paris Agreement target, which shifted from a 'below $2{ }^{\circ} \mathrm{C}$ ' to a 'well below $2^{\circ} \mathrm{C}$ ' formulation.

Of course, there are several uncertainties that are not addressed in those probabilistic temperature projections. Therefore, future investigations might shift the estimates for a $50 \%$, lower, or higher chance of staying below $1.5{ }^{\circ} \mathrm{C}$ warming level relative to the pre-industrial level.

Figure 12.4 shows the global mean surface air temperature projections, and their $66 \%$ and $90 \%$ ranges, for the three scenarios developed in this study. The reference scenario is shown in red, the $2.0{ }^{\circ} \mathrm{C}$ pathway is shown in blue, and the $1.5{ }^{\circ} \mathrm{C}$ pathway is shown in green. For historical temperatures, a mixture between ocean-surface and land-surface air temperatures is shown, namely the HadCRUT4 dataset. The most recent estimate by the IPCC of the pre-industrial air surface temperature levels is that they were around $0.97{ }^{\circ} \mathrm{C}$ below the 2006-2015 levels. The median projections of the three scenarios are shown in thick solid lines.

As a first approximation, the global mean temperature is proportional to the sum of all historical $\mathrm{CO}_{2}$ emissions. In a similar vein, sea-level rise is the sum over all past temperature rises relative to the pre-industrial level. Combining these two approximations yields the rule of thumb that sea-level rise is proportional to the double integral of $\mathrm{CO}_{2}$ emissions. Therefore, whereas temperatures are relatively agnostic about when $\mathrm{CO}_{2}$ emissions occurred, sea-level rise will be higher the longer ago the $\mathrm{CO}_{2}$ emission occurred.

This proportionality has implications for our scenarios. As we saw previously, our scenarios are relatively low in terms of radiative forcing early in the twenty-first century compared with the lower scenarios of the SSP and RCP sets. Towards the end of this century, the strongly net negative emissions of the SSP1_19 scenario will cause radiative forcing (and approximate temperature) to be similar under SSP1_19 and our $1.5^{\circ} \mathrm{C}$ scenario. That our scenarios will first entail lower and then similar forcing and temperature levels suggests that the implied sea-level rise will be lower for the second half of the twenty-first century and beyond, even though the 2100 temperature level might be similar. This is a clear benefit of our scenarios and should be investigated further in the future.

Thus, there is clearly an advantage in undertaking concerted early action rather a slower decline in emissions followed by strong negative emissions. This is important. However, in the larger scheme of things, it is clearly a second-order effect. Even under the strongest mitigation scenarios, we cannot expect sea-level rise to stop any time soon. To halt sea-level rise in the $21^{\text {st }}$ or even the twenty-second century, we will require massively negative $\mathrm{CO}_{2}$ emissions, drawing back out of the atmosphere a lot of the $\mathrm{CO}_{2}$ that we emitted this century. Therefore, even under our low $1.5^{\circ} \mathrm{C}$ and $2.0^{\circ} \mathrm{C}$ scenarios, the expected sea-level rise by 2100 will be above $30 \mathrm{~cm}$ relative to the 2010 levels_-and will continue to rise to 2100 (Fig. 12.5). 


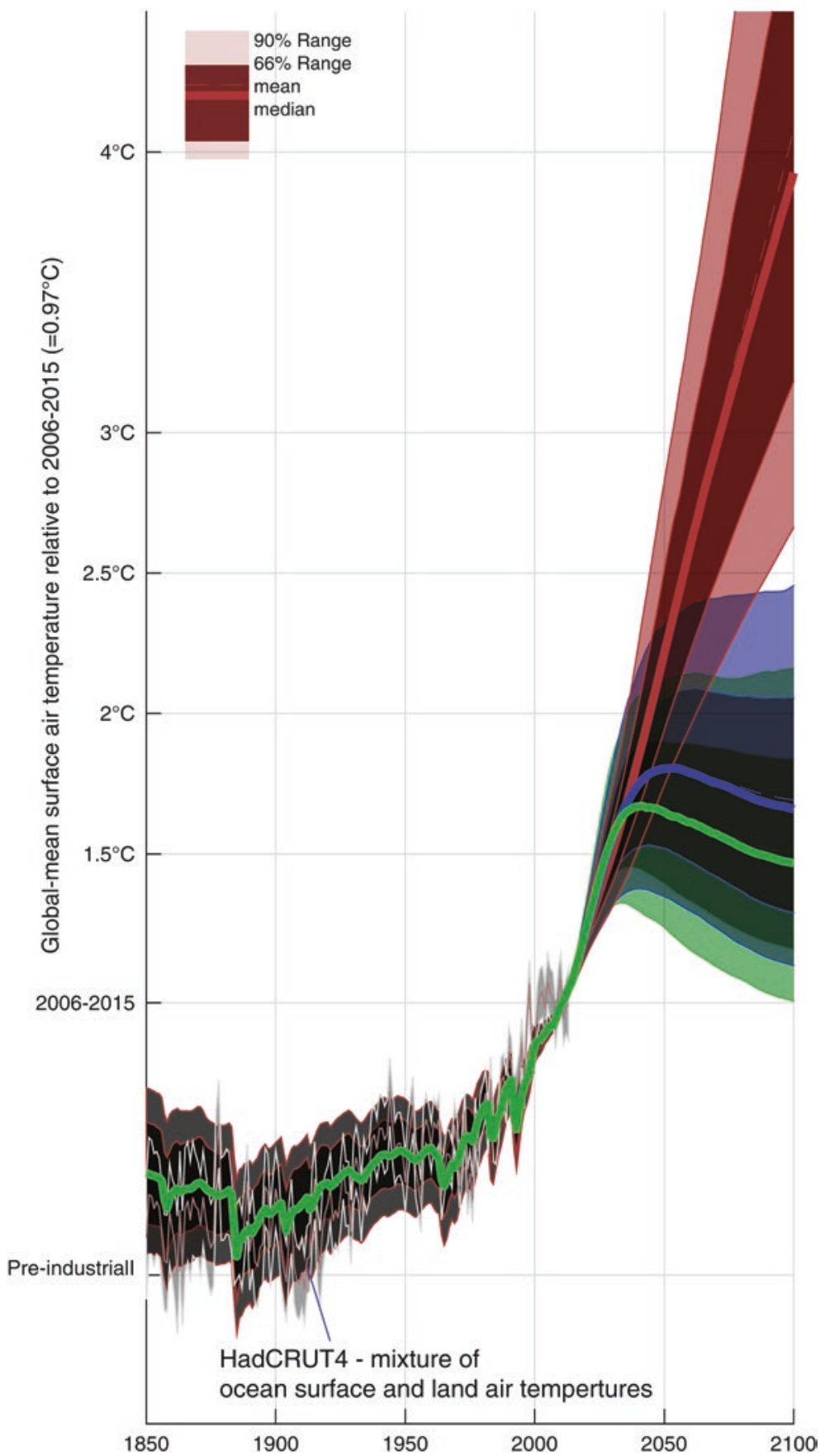

Fig. 12.4 Global-mean surface air temperature projections 


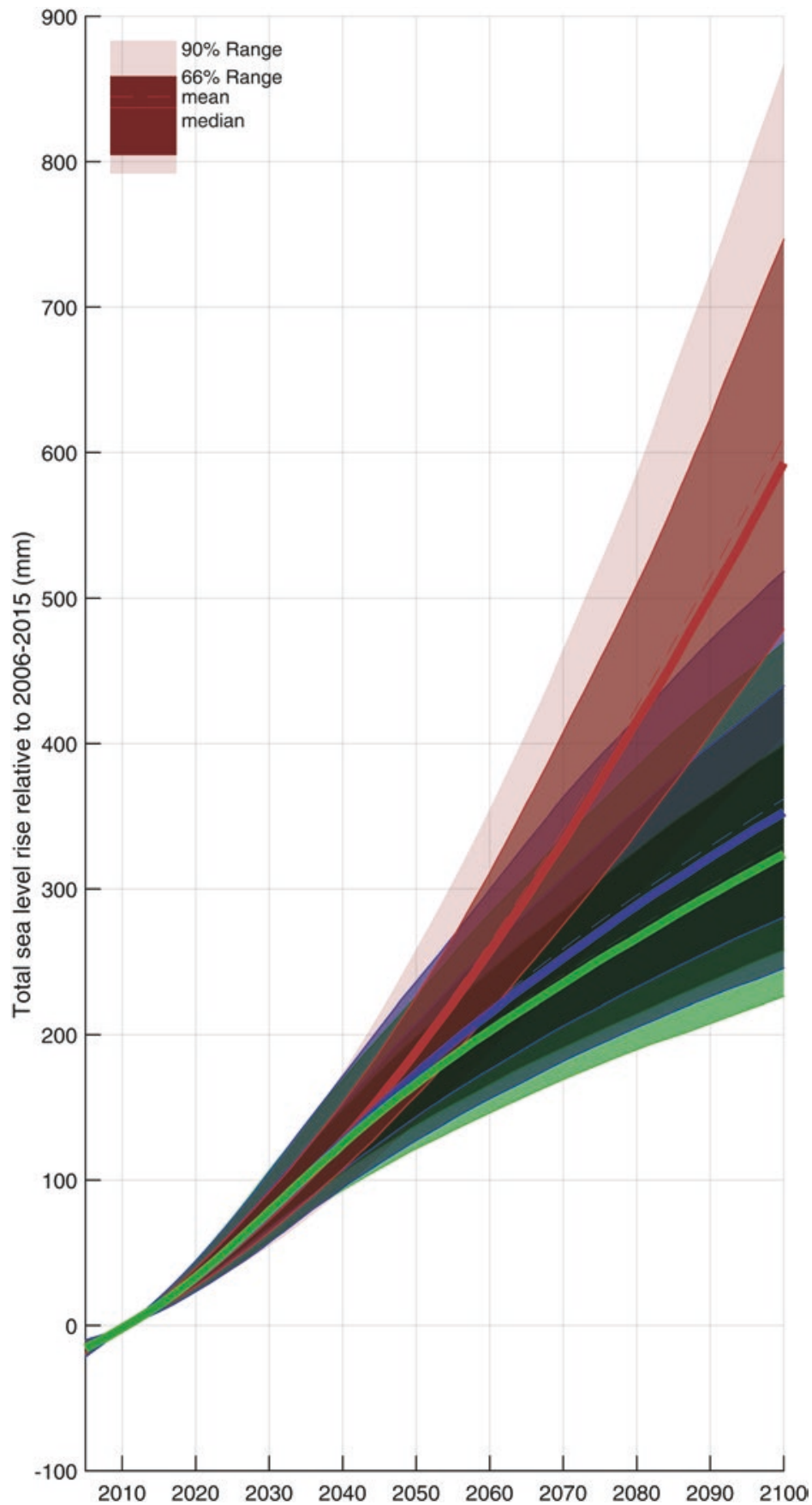

Fig. 12.5 Global-mean sea level rise projections under the three scenarios developed in this study 


\section{References}

Ricke, K.L., Orr, J.C., Schneider, K. and Caldeira, K., 2013. Risks to coral reefs from ocean carbonate chemistry changes in recent earth system model projections. Environmental Research Letters, 8(3), p.034003.

Nauels, A., Meinshausen, M., Mengel, M., Lorbacher, K. and Wigley, T.M., 2017. Synthesizing long-term sea level rise projections-the MAGICC sea level model v2. 0. Geoscientific Model Development, 10(6).

Open Access This chapter is licensed under the terms of the Creative Commons Attribution 4.0 International License (http://creativecommons.org/licenses/by/4.0/), which permits use, sharing, adaptation, distribution and reproduction in any medium or format, as long as you give appropriate credit to the original author(s) and the source, provide a link to the Creative Commons licence and indicate if changes were made.

The images or other third party material in this chapter are included in the chapter's Creative Commons licence, unless indicated otherwise in a credit line to the material. If material is not included in the chapter's Creative Commons licence and your intended use is not permitted by statutory regulation or exceeds the permitted use, you will need to obtain permission directly from the copyright holder.

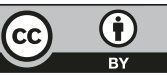

